\title{
The natural history of violence
}

\author{
Claire Russell Psychoanalytic practitioner \\ W M S Russell Department of Sociology, University of Reading
}

\begin{abstract}
Authors' abstract
In the past, human violence was associated with food shortage, but recently it has increased even in relatively well-fed societies. The reason appears from studies of monkeys under relaxed, spacious conditions and under crowding stress. Uncrowded monkeys have unaggressive leaders, rarely quarrel, and protect females and young. Crowded monkeys (even well-fed) have brutal bosses, often quarrel, and wound and kill each other, including females and young. Crowding has similar behaviour effects on other mammals, with physiological disturbances including greater susceptibility to infections. All this appears to be a regular response to overpopulation, reducing the population before it has depleted its natural resources. Human beings, like monkeys and other mammals, need ample space, and become more violent when crowded. Human history is marked by population cycles: population outgrows resources, the resulting violence, stress and disease mortality cuts down the population, leading to a relief period of social and cultural progress, till renewed population growth produces the next crisis. The modern population crisis is world-wide, and explains the increase of violence even in well-fed societies. The solution to the problem of violence is to substitute voluntary birth control for involuntary death control, and bring about relaxed conditions for a reduced world population.
\end{abstract}

\section{Introduction}

'In 1900, a visitor from another sphere might reasonably have decided that man, as one met him in Europe or America, was a kindly, merciful and generous creature. In 1940 he might have decided, with an equal show of justice, that this creature was diabolically malignant. And yet it was the same creature, under different conditions of stress'. These words were not in fact published in 1940, when the Second World War began in earnest. They occur in a kind of history of the future, published in 1933, the year of Hitler's accession to power. The book was The Shape of Things to Come, and the writer was H G Wells. In this passage we have the central notion on which we shall enlarge in this paper. It is the notion that the same creature, the same species, can be kindly and merciful or diabolically malignant, under different conditions of stress. ${ }^{1}$

For thousands of years, there have been two schools of thought about human aggression and its expression in violent crime, riot and war. Some ${ }^{\text {s }}$ people have said that human aggression is human $\vec{\circ}$ nature, an innate disposition in man. Other people, $\overrightarrow{\vec{\omega}}$ like Wells, have taken the view that human aggres- $\mathcal{O}$ sion is a response to intolerable frustrations, and $\overline{\overline{3}}$

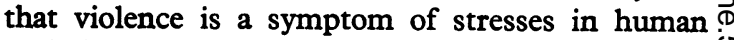
societies and in their relations with their natural $i$ surroundings. The records of past history, right up $\vec{\partial}$ to the middle of the present century, appear to $\infty$ favour this second view, that violence is a reaction ㅇ to stress, notably the stress of shortage of food. Clear evidence for this connection can be found by $\mathcal{D}$ studying the incidence and severity of public $\frac{\mathbb{O}}{\square}$ violence in many times and places, such as Imperial $\frac{\Phi}{3}$ China, Japan in the seventeenth to nineteenth $\frac{\partial}{0}$ centuries, Tudor England, eighteenth century France, and medieval Europe from Brittany to $\vec{\theta}$ Bohemia. By 1932, evidence of this kind had copf cै vinced most civilised people that human aggressio is a response to stress, and not an innate and inerof dicable taint. This was the verdict of the American Psychological Association, replying in that year to a questionnaire, by a majority of 346 to ro.

\section{Man's inherent aggressiveness?}

But in the I950s voices began to be heard again in favour of man's inherent aggressiveness. This change of opinion results from events in modern highly industrialised societies of W. Europe and N. America. These affluent societies have much higher national incomes than other nations, or that they themselves had in earlier periods. True, it has been estimated that nearly one-seventh of the British people, and more than one-quarter of the American people, are living in serious poverty. Nevertheless, the affluent societies are genuinely affluent in one important sense. By comparison with Tudor England or Imperial China or modern India, most people in the affluent societies are free from really serious shortage of food. If violence is a response to stress, should not this real improvement have the effect of substantially reducing violence in these societies? What has actually happened is precisely the reverse. In England and Wales, between 1950 and 1960, the annual number of violent crimes per 100,000 people more than doubled. In the United States, between 1960 and 1970, violent crime increased nearly six times as 
fast as population. Similar figures have recently been reported by Radzinowicz and King for a number of other affluent societies. ${ }^{2}$ Does all this mean that people are indeed inherently aggressive whatever their conditions, or even, as has been quite seriously suggested, that young people nowadays are not being frustrated enough ?

\section{Studies of monkey societies}

At this point we can get new insight into the problem from studies of the simpler societies of monkeys (including apes), and especially from comparing their behaviour in the wild and in the zoo. Studies of monkey societies in the field were rare until the r950s, but by now we have accounts of about a score of species in the wild, at least eight of these same species in zoos or other close forms of captivity, and some species, notably rhesus monkeys, in a variety of different intermediate conditions. We thus have a wide basis for comparing monkey behaviour in the wild and monkey behaviour in the zoo. In 1964, the Institute of Contemporary Art organised a series of lectures on violence, and we were asked to talk about violence in animals. The time seemed ripe for a survey of the field reports on monkey societies, and when we made this survey, and compared the results with those obtained in zoos, a remarkable contrast appeared, which has been fully confirmed by all subsequent findings.

From this survey and comparison, we find that differences between wild and zoo behaviour are common to all the species studied, and amount to a total change or reversal of all aspects of social interaction and social life. The first and most striking difference is in respect of quarrelling and violence. In monkeys living under completely relaxed conditions in the wild, quarrelling is always rare and violence is practically non-existent. In monkeys living under the stresses of a zoo enclosure, quarrelling is always frequent and violence appreciable, sometimes leading to serious wounds and death. This contrast applies to all the species studied: any species in the zoo is more quarrelsome and violent than the same or any other species in the wild. Hans Kummer made a direct comparison of hamadryas baboons living in the wild in Ethopia with hamadryas living at the Zürich Zoo. He found that aggressive acts by males were 17.5 times as frequent in the zoo as in the wild, and that serious bite-wounds were commonplace in the zoo, though they never occurred in the wild. This contrast seems to be typical of all monkey species studied.

The zoo monkeys are clearly getting an ample food supply, and can be regarded, so to speak, as materially affluent societies. What they lack is space, since a band of monkeys in the wild normally roams an area of several square miles, whereas a zoo community must make do with an area of several hundred square yards. A prominent feature of monkey behaviour in the wild is the extent to which they keep out of each other's way, except when they make contact by mutual consent for grooming, mating or huddling in cold weather. This elbow-room, or social space, is squeezed out when monkeys are crowded, and as a result of continual jostling and intrusions they become quarrelsome and violent. Experiments in captivity have confirmed the close relationship between crowding and aggression, for instance, observations on rhesus monkeys by $\mathrm{C} \mathrm{H}$ Southwick at the Calcutta Zoo and by Hilary and Martin Waterhouse at the Bristol Zoo, and by B K Alexander and E M Roth on a band of Japanese monkeys captured as a band and imported, still all together, to an institute at Beaverton, Oregon (USA). At Calcutta, halving the cage area for the same number of monkeys roughly doubled the amount of aggressive behaviour. At Beaverton, reducing the size of the enclosure by a factor of 40 resulted in a 20-fold increase in the number of violent mobbing attacks in which many monkeys combined to persecute single victims. At Bristol, halving the number of monkeys in the same enclosed area reduced the frequency of fights by 75 per cent.

\section{Social organisation of monkey bands}

The astonishingly uniform peacefulness of wili monkey bands reflects the nature of their sociat organisation. The forms of social structure an $\bar{\varphi}$. political control vary considerably between and ${ }^{+}$ even within monkey species, but the one form never found in relaxed wild conditions is arbitrary dictatorship by a single individual. There is often a top leader, usually but not invariably male, but he is not necessarily the toughest individual, but the one most capable of making friends and enlisting reliable support from male colleagues, and of securing the approval of the females. For instance, Graham Saayman studied a cynocephalus baboon band on the Honnet Nature Reserve in the Transvaal. He made counts of the different activities of the three adult males present, named by him Yogg, Sickle Tail and Barker. Quarrels were rare - less than one per monkey per day - but Saayman observed long enough to show that Barker was by far the most aggressive male, and by far the most domineering. He drove another male out of his way $\infty$ most often, and was least often displaced himself. N Yogg was the least aggressive and domineering, with N Sickle Tail intermediate. However, Barker was kept $\frac{\omega}{\sigma}$ in check because Yogg and Sickle Tail spent much of their time close together, and regularly combined to threaten off the aggressor. The unaggressive Yogg was top leader. He led the way most often in band movements, and most often intervened to stop quarrels among females and young males. He was $\mathbb{\mathbb { D }}$ most often courted by females on heat, he groomed $\frac{\rho}{\mathrm{D}}$ them and was groomed by them most often, and 
most often mated with them. The aggressive Barker scored low on all these counts. Yogg was seen to ejaculate 18 times, Sickle Tail II times, and Barker only 6 times. Similar observations have been made in other species in the wild, and it is clear that under relaxed conditions success in both sex and politics go to the friendliest and least aggressive male.

These observations have recently been supplemented by a detailed investigation of rank criteria in chimpanzees made by Vernon Reynolds and Gillian Luscombe. The observations were made at a USAF base in New Mexico, and concerned a community of redundant chimponauts. These chimps had all been trained to work in space vehicles. As everyone knows, human astronauts have taken over their jobs. The apes were therefore gathered together in honourable retirement in a spacious enclosure of 30 acres at Holloman Base. They rapidly resynthesised a community similar in many ways to those Vernon Reynolds had observed in the wild in Uganda. In these relatively relaxed conditions, Reynolds and Luscombe made observations for six days on 34 individuals. Each individual was scored for food consumption and in particular for the amount of preferred foods he obtained. A clear-cut rank order emerged, with marked differences between high-ranking individuals, who ate plenty of their favourite fruits, and low-ranking chimps, who had to make do with monkey pellets.

Records were also made, for each individual, of all his social interactions with other individuals, that is, every time he did something in relation to another individual. These interactions were classified into two groups: aggressive and friendly. Aggressive interactions included slaps, bites and stand-up threat display with hair erect and arms bowed, which made the threatened individual take to flight. Friendly interactions included grooming, greeting, play and the like. When all the scores were compared, it was found that the chimps of high rank, evidently the most self-assertive ones, were not the ones with most aggressive behaviour, but those with most friendly contacts, the best-liked individuals. The most successful chimp of all had nine times as many friendly contacts as the average score. The chief way to win friends and influence people was apparently to perform a noisy but unaggressive display, quite different from the threat display: this cheerful hooting and banging about seemed to attract friendly attention and interest, and led to numerous friendly contacts and high rank and privileges as a result. When two or more bands of chimps meet in the wild at a fruit-tree which has just come into season, they engage in a regular beat session which may go on for as long as 50 minutes, drumming on tree roots and rushing about the trees. It is possible, in the light of the chimponaut study, that this helps to arrange ranks and priorities among chimps who do not know each other well. What the study shows, above all, is that under relaxed conditions self-assertion and aggression are totally $\frac{c}{d}$ different things, expressed in posturally different $\cong$ displays. In a wild monkey band, aggressiveness is $\underset{F}{F}$ not the way to social advancement.

\section{Crowding stress}

In the zoo, under sufficient crowding stress, the picture can be totally different. Dictatorship by a physically powerful individual is a common $\vec{\nabla}$ observation here. In rhesus colonies observed by Michael Chance at Regent's Park and by Vernon ${ }^{\infty}$ Reynolds at Whipsnade, the top male was in each $\vec{O}$ case far separated in rank from the second one. The $\overrightarrow{-}$ top male in each was a complete dictator, of whom ${ }_{\sigma}$ all other monkeys were terrified. In a group of chimpanzees in a small enclosure at Regent's Park, observed by Caroline Medawar, we can see the $w$ extreme contrast to the 'civilised' community at: Holloman. In this Regent's Park group, severely crowded, the boss was a strong male with a positive응 dislike for personal friendly contacts: he would attack and viciously wound any of his subjects whocs made friendly approaches even to each other. In these conditions there has evidently been a total $\frac{\mathbb{Q}}{3}$ reversal: high rank is now attained by brutalo aggression and nothing else.

It is no wonder the result is frequent quarrelling $\vec{\varphi}$ and not infrequent violence. A dictator monkey a crowded colony, touchy about intrusion disturbance in the confined space, is constan liable to attack subordinates. He may suddenly rush upon a group of neighbours and scatter them-just as the police (according to the well-documented $\mathrm{D}$ Walker Report) suddenly scattered a group of peaceful demonstrators in Lincoln Park, during the 'police riot' in Chicago in the summer of 1968. In a study of 118 quarrels described by Reynolds among the rhesus colony at Whipsnade, Claire Russell and I were able to identify a number of processes which in the wild make for peace but which under pro- tracted stress of crowding actually spread and 3 . amplify and prolong and intensify quarrels. A wild $\bar{\varnothing}$ leader will repress a quarrel between two others by means of a mild threat; the zoo dictator will simply attack one of them as a punishment. In the wild, a monkey momentarily frustrated by a superior may work off his feelings by redirecting resentment into a threat against some monkey of still lower $\tilde{N}$ rank, who can simply move away with no harm N done. In the crowded community, a monkey N punished by the dictator will go off and attack $\sigma$ somebody else by way of redirection, illustrating the observation of the great law reformer, Sir Samuel Romilly, that 'cruel punishments have an inevitable tendency to produce cruelty in the people'. In this : way recurrent vicious cycles could arise, $A+{ }_{0}^{-}$ punishing $B, B$ redirecting attack to $C, A$ punishing $\vec{\Phi}$ $B$ again for this attack, and so on. As Hans Kummer $\frac{P}{\mathrm{D}}$ showed first in hamadryas baboons, when one $\frac{\circ}{0}$ 
monkey threatens, a neighbouring monkey will often threaten in the same direction, even if he cannot see the object of the first one's threat. In the wild, this automatic reaction ensures prompt support for the leader from his colleagues, who are always close to him, in suppressing by threat and without violence, aggression by subordinates. In the zoo, this same reaction causes other monkeys to join in a quarrel on the side of the aggressor. By all these means, quarrels reverberate round the society. Monkeys of low rank are liable to become the butts of mass redirection by all the others; this mass redirection can reduce an individual to the status of an outcast, having no more social relations with anyone in the community. This happened to a male at Whipsnade, who finally had to be removed when the others broke his arm in a final unprovoked persecution.

An alternative possible outcome of mass redirection could be a form of war. In relaxed conditions in the wild, bands of monkeys respect each others' territorial ranges and never fight each other. In 1938, C. R. Carpenter trapped over 500 rhesus monkeys in India, and shipped them to the islet of Cayo Santiago, off Puerto Rico. Only 409 survived the land and sea journeys. Monkey transport was then carried out in frightful conditions: Carpenter himself was a pioneer in improving it. Lethal fighting occurred in the crowded bamboo cages on the Indian railways, and the mothers on the voyage were under such stress from food and spaee shortage that at least eight of them killed their babies. On arrival at the islet of Cayo Santiago, the new monkey societies were free to roam at large, but they were suffering from the after-effects of very severe stress, and the social machinery of leadership selection was impaired. During the first year on the island, there was heavy mortality from lethal fighting, and in one of the bands that formed there arose an aggressive dictator called Diablo, more autocratic and quarrelsome than even the zoo bosses, being five times as aggressively domineering as the second male in the band, whereas even the dictator at Whipsnade was only 1.5 times as aggressively domineering as his second. Diablo's subjects were thus under even greater pressure than zoo monkeys, but they were not confined by the walls of an enclosure. The resulting mass redirection turned outwards, the band invaded the ranges of other bands, and virtually conquered the whole islet. Carpenter now removed Diablo and caged him. The band at once withdrew into a normal territorial range. After some post-war disturbances, in which the monkeys worked off their remaining resentments, a moderate leader took over, territorial rules were properly observed, and peace returned to the islet.

We have now seen that rank criteria, social structure and a variety of social interactions all change completely under stress, especially under crowding. Another change, of major importance, is typified by the rhesus mothers on the voyage who killed their babies. When brute strength becomes the basis of social order, females and young, as the weakest members of the society, are the principal victims. In relaxed conditions in the wild, male leaders show the utmost chivalry towards females and young, and protect them instantly from even mild attacks by others. Under the stress, the dictators of the zoo colonies, such as the Whipsnade dictator, are capable of savagely biting and even killing females and young. In a colony of hamadryas baboons at Regent's Park, observed in the r920s by Sir Solly Zuckerman, eight out of sixty-one males died by violence, but thrity out of thirty-three females and five out of five babies were killed in this way.

Now allowing for simpler social organisation, all other mammal species that have been studied show in the same kind of reversal of social behaviour under $\omega$ stress, notably under crowding, culminating in the $\triangleright$ brutal social inequality, unrestrained violence, and 을 murderous cruelty to females and young. Mammals, in short, have two totally different kinds of social is behaviour, 'kindly and merciful' on the one hand, $\mathbb{D}$ 'diabolically malignant' on the other. Some social mechanisms, as we have seen, are actually designed, with beautiful economy, to promote peace under relaxed conditions and violence under stressful $\vec{\theta}$ conditions. The fundamental change is in parento 0 behaviour, from a protective to a competitive attitude. For, as the Dutch zoologist, Adriax? Kortlandt has pointed out, parental behaviour is the starting point of all other mammalian social behaviour. In its relaxed and positive form, and in its stressful and negative form, it is, so to speak, the origin of love and hate.

\section{Violence and population reduction}

The evolutionary advantages of positive social behaviour are obvious. But what could be the significance of the diabolically malignant behaviour 3 under stress, and the triggers and switches which $\delta$ appear to effect the reversal? Now studies of mammals with short generation time, such as rats 0 and voles, have shown that a population bred in a confined space, though supplied with unlimited $\frac{D}{2}$ food, will not exceed a certain density. As soon as the density reaches a certain value, the reversal of $\infty$ behaviour begins, and the tension and violence and $N$ attacks on females and young have the effect of $N$ halting population growth and even reducing the population for some time. V C Wynne-Edwards has pointed out that if a population of animals only $\stackrel{C}{?}$ began to fight when its food supply was running $\stackrel{\Phi}{\oplus}$ short, that supply could be irretrievably depleted. By reacting to population density, a population can be reduced in time to allow the food supply to $\mathbb{D}$ recover. The effects of crowding and violence are $\frac{\Phi}{\mathbb{Q}}$ not restricted to death by wounds. There are also 
physiological effects, which render the animals vulnerable to other causes of death. These effects are most pronounced in low-ranking individuals, who obviously suffer the worst stress; they have been studied in crowded house-mice, deermice, voles, woodchucks, rats, muskrats, rabbits and dogs. The visible signs of the disturbance are enlargement of the adrenals and spleen and shrinkage of the thymus. There is a direct increase of certain stress diseases, chiefly of the kidneys. There is increased susceptibility to drugs, poisons and radiation. Most important, there is a breakdown of the body's defences, so that the animals are more vulnerable to external parasites (many of them carrying disease), more easily infected by disease organisms, and more likely to die of their infections. Hence a community weakened by crowding is liable to succumb to epidemics, which complete the crash of the population. For instance a confined population of rabbits, when it reached a high density, collapsed under a lethal outbreak of the virus disease myxomatosis.

Field observations confirm that these effects are an important component of the response to population crisis, for instance observations on snowshoe hares, lemmings and voles. During the r96os, Alberto Vizoso showed that a number of viruses were present in healthy populations of red squirrels in England, without any harmful effects on the animals. $\mathrm{He}$ also obtained viruses from red squirrel populations undergoing epidemics. His results 'suggest that we may have something which is commonly present in red squirrel populations, which may exist in a latent form, and which is capable of causing overt disease and a high mortality rate under conditions which exert stress' on the animals. It is quite possible that these viruses were involved in the drastic crashes of red squirrel populations in Britain in the early 2oth century, after the species had reached a level of gross overpopulation in the I9th century.

In 1916, five Sika deer were released on an island of 280 acres in Chesapeake Bay. They bred freely, and in 1955 the herd numbered more than 180 , a density of about one deer per acre. In 1958, there was a sudden 'die-off', and I6I carcases were recovered. The population finally stabilised at around eighty. The carcases of the deer that died in 1958 were compared with specimens shot in earlier and in later years; their glands gave evidence of severe physiological stress. Most of them had literally died of stress or shock; two had succumbed to hepatitis, probably through weakened immunity. At the time of the die-off, the food supply was still ample. and the carcases were sleek and had deposits of fat. If the deer population had increased much further, they could have irretrievably depleted the food supply on the island, and then they would all have died out. This and much other evidence suggests that all the responses to overcrowding, behavioural and physiological, have been evolved to $\frac{c}{d}$ reduce a population drastically for more than a $\cong$

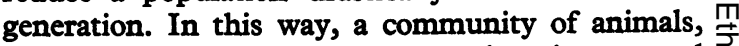
which is in danger of outgrowing its natural resources, will be decimated before it has irretrievably depleted these resources, and so give them time $\overrightarrow{\vec{F}}$ to recover.

For mammals, then, we have now a clear picture. $\frac{\mathrm{C}}{\sigma}$ Under relaxed conditions, they are incredibly $\frac{\bar{\sigma}}{\bar{c}}$ peaceful and, so to speak, civilised. Under popula- $\vec{\nabla}$ tion pressure, their societies are brutally unequal, cruel, tense and violent. Where man is concerned, क we can make no such easy comparison. For man has $\vec{\circ}$ probably never enjoyed completely relaxed condi- $\vec{\overrightarrow{ }}$ tions. Technological advance is the outcome of $\omega$ human intelligence. But it has always hit human societies as if it were an external force, since they have never, till very recently, even recognised the $i$ need to regulate and allow for its effects. Every major technological advance has changed the $\odot$ relation between human societies and their natural 0 surroundings and resources, increasing the potentialities for food production, and so making $\$$ possible an increase in population. Every time, the $\frac{\mathbb{C}}{\mathbb{P}}$ population increase has gone on without regulation, $\frac{\mathbb{D}}{3}$ so that sooner or later population outstripped resources. The result has been that man has been $\stackrel{\Phi}{-}$ under virtually continuous population stress, and $\vec{\theta}$ hence virtually continuous social inequality, tensiog co and violence. As a result, some people have ever. supposed that these evils are the normal inherefint lot or nature of man. But while all mammals are capable of fiendish cruelty under stress, man differs from them all in having an even more highly developed positive parental urge. This is clear from $\stackrel{2}{\Rightarrow}$ the long and increasing duration of parental care in man, and from the unique social achievements of $\frac{}{5}$ our species, with refinements of social welfare arrangements between adults, all stemming from our parental behaviour. Even under frightful stresses, where almost all mammals would kill their ${ }_{-}^{\infty}$ young, many human beings continue to love and 3 . protect them, even at great sacrifice to themselves. It is not the violence in men's desperately stressful career that should astonish us, but the quality of $\mathrm{O}$ human intelligence and human feeling in the most awful circumstances.

Nevertheless, under sufficient stress, a proportion of human beings do wound or kill even their own $N$ children, and thoroughly mammalian atrocities don occur in man. We do not have human societies in N totally relaxed conditions for comparison, as we do with monkeys; but we can compare human societies under greater or lesser degrees of stress, in different ${ }^{\circ}$ places and times. When we do so, we find every indication of corresponding differences between positive and negative social behaviour, amply enough to suggest that, if we could eliminate $\vec{D}$ population stresses altogether and for ever, our $\frac{?}{\mathrm{D}}$ societies could be as free, friendly and peaceful as 
those of wild monkeys, and of course infinitely more creative.

\section{Social space}

To begin with, there are many indications that human beings, like monkeys and other mammals, have a definite need for ample space, and a definite reaction to being crowded. Stanislav Andreski made observations in transit stations for released prisoners of war on their way home. When these men sat down to a meal in the canteen, some of them would draw chalk lines round their bodies to show the elbow-room they wanted, a perfect visualisation of social space. Paul Leyhausen observed that when prisoners of war were released into a new camp they would each start to fence off a part of the floor space with string or pieces of cardboard, to define an individual territory. Edward $T$ Hall found that people, like higher animals, tend to maintain characteristic distances between them except when engaged in intimate contact by mutual consent. T S Brindley photographed more than fifty bus queues in Reading, Berkshire, and found that 'interpersonal distances between strangers in bus queues are remarkably consistent, Eight-two per cent of the measurements fell within the range 2 ' to $2 \cdot 5^{\prime \prime} .8$

Living in crowded conditions forces people to spend more time in close proximity to each other than they would choose. When we compare different places at the same time, under greater or lesser degrees of crowding stress, we can find plenty of evidence for an increase of violence under more crowded conditions. At Newcastle, the city planning department in the rig6os made a study of various social and medical symptoms in different districts of that city, differing in many ways. They found the sharpest comparison was between the most crowded and least crowded thirds of Newcastle. The most crowded third produced more than five times as many offences against the person, more than four times as many larcenies, seven times as many people on probation, three times as much juvenile delinquency, more than five times as much venereal disease, and 43 per cent more prenatal deaths. Essentially similar findings were made about the same time in Chicago. ${ }^{4}$ In his Autobiography, H G Wells thus described his life in a slum at Westbourne Park. 'I looked, so to speak, through a hole in my life of some weeks more or less, into a sort of humanity coarser, beastlier and baser than anything I had ever known before... I think the peculiar unpleasantness of that episode lies in the fact that we were all too close together. We were as congested . . . as zoo monkeys'.

Comparison in time provides a more impressionistic picture, but in some ways the contrasts shown are more striking, for the scale is bigger. The more favoured human societies have been able repeatedly to increase their supply of food and other resources through technological advance, and hence support an increased population. Every time this happened, however, their populations increased beyond even the new resource level, producing scarcity: in the words of H G Wells (in Men Like Gods) mankind 'spent the great gifts of science as rapidly as it got them in a mere insensate multiplication of the common life'.

The essentials of the situation were clearly worked out by Robert Malthus in publications between I798 and 1830, and outlined even earlier, in I793, by Hung Liang-Chi, educational commissioner of Kweichow. For all the complexities of demography, in the long run (migration apart) population change is a function of ('crude') birth-rate and death-rate, reckoned as numbers per hundred or thousand per year. If the birth-rate is higher than the death-rate, the population grows. The trouble is that the growth is by compound interest, since the more people there are, the more offspring they can breed. A calculation has been made which shows the fantastic implications of this. If mankind had sprung from a single couple, living about 12,000 years ago, shortly before the coming of agriculture, and if there had been one more birth than deaths per hundred per year (a modest I per cent increase per year), then today the world population would form 'a sphere of living flesh, many thousand light years in diameter, expanding with a radial velocit many times faster than the speed of light'. In reat ' life, as opposed to the wonderland of mathematics, nothing of the kind can happen. So in real life, when a population increases even at this modest rate, sooner or later one of two things must happeneither the birth-rate comes down, or the death-rate goes up, and the increase is checked.

\section{Violence and population cycles}

Until recent times, human civilised societies tended to have high normal death-rates (3-4 per cent) but even higher birth-rates (3.5-5 per cent); hence their populations grew. They did not end up as expanding spheres of flesh etc. Instead, every so often, they began seriously to outgrow their current supply of resources. They then entered a period of $\frac{D}{O}$ what we have called population crisis, with welldefined characteristics. The economic effects $N$ included price inflation and fall in real wages (which can be shown in many times and places to 0 depend closely on population growth), unemployment and often grandiose building projects (designed to absorb labour) which further depleted $\varrho$ resources. The political effects included reduced $\mathbb{D}$ freedom of the individual and a tendency to $\stackrel{?}{+}$ tyrannical government. The cultural effects included $T$ narrow specialisation, distrust of new ideas $\frac{P}{\mathbb{D}}$ (especially if simple and wide-ranging), superstition, $\cong$ intolerance and restrictive censorship. The social $\unrhd$ 
effects included greater inequality between classes, greater difficulty in moving from lower to higher classes, social tension and a tendency to redirect resentment to defenceless minorities. The behavioural effects (very much as in monkeys and other mammals) included increases in all kinds of violence, involving violent crime, class conflict, the persecution of minorities, and all kinds of atrocity; the usual protective attitudes to women and children were impaired. The society as a whole might break down into anarchy, and was particularly vulnerable to foreign invasion and conquest. Meanwhile the inadequate food supply resulted in famines and chronic malnutrition, and this (combined with crowding and all kinds of social stress) rendered the people liable to high mortality from epidemics.

As a result of such a population crisis in a society, the population was drastically cut down. For a time, things were better, because the population was much reduced relative to its current resource supply. Hence such relief periods were times of economic, political, social and cultural advance, often called renaissances. These relief periods were particularly fruitful in Europe in producing sustained cumulative technological and social progress, not because of any inherent superiority of Europeans (there is no evidence for and plenty of evidence against any such inherent differences between peoples), but because until recently Europe had a far lower population density than that of any other civilisation. However, in Europe as elsewhere, these relief periods were always brought to an end by renewed population growth, which eventually ushered in another population crisis. In this way, history is everywhere broken into population cycles of crisis and relief.

We have described population cycles of this kind in the history of Europe, North Africa, the Near and Middle East and Central Asia, China, and the civilisations of the New World. In more recent studies (unpublished), we have found population cycles in the history of India, Sri Lanka, South-East Asia and Japan, and (from archaeological evidence) in prehistoric societies in (for instance) Southern Britain, the south-western United States and the Marquesas Islands. The population crash that ends each cycle reflects a prodigious quantity of human misery and waste. What population cycles mean for the individual may be seen by looking at his or her longevity. Between the mid-I3th and the mid-r5th century in England, for instance, the expectation of life at birth for a male dropped steadily from about 35 years to about 17 during the population crisis, and rose again to about 33 during the recovery period. On the world stage, population cycles are associated with such great discontinuities of history as the fall of empires. In the past, the population cycles of different regions were not necessarily in phase with each other. Cycles could be out of phase even within continental regions. Thus the first and worst outbreak of the Black Death in Western 3 Europe (1348-9) caused few casualties in Bohemia, $\stackrel{\mathbb{\Omega}}{\Omega}$ where population was still in better balance with resources, while the people of the rest of the region, weakened by malnutrition and stress, died in their? millions. Now, however, perhaps for the first time, the cycles are all synchronously in phase, and the present population crisis is worldwide. Though the pattern of specific scarcities may differ in different은 places, no country in the world is free from over-? population and scarcity (including scarcity of: housing space), expressed, for instance, in prices inflation. The characteristics of population crisis wehave listed will readily explain why violence hasincreased in recent decades even in the affluent $\vec{\omega}$ societies.

\section{Many-generations effect}

We may now turn to another feature which $\vec{\circ}$ population crisis in human societies shares with population crisis in animals. The whole complex of 5 violence, in response to stress, appears designed to $\vec{p}$ produce effects over several generations, thusp reducing populations long enough to permitक्षे complete recovery of natural resources. In animals as socially simple as voles, this many-generations effect is probably limited to physiological repro- $\vec{c}$ ductive disturbances. In animals with appreciabe amounts of parental care, including even mice a further many-generations effect can be produced 6 jo means of disturbances in the upbringing of young. The stress which causes some parents eveno to kill their offspring causes others to bring them upo with some degree of neglect or hostility, and the effects of such early experience lead to violence in $\vec{b}$ the next generation, who in turn bring up their own young with inadequate or distorted parentaf behaviour. It is to be expected that this stres? effect would gradually diminish after removal of the original stress, and finally fade out altogether, $\mathbb{\mathbb { D }}$ The Biblical estimate, that the stresses and violences of parents are visited on their children 'unto the third and fourth generation', may not be far out? If this were not so, the relief periods in human history between crises would be just as violent as the crisis periods themselves, whereas they arep appreciably less violent, as we have seen. This maye. give us reason to hope that, if we do solve then population problem for good, the residual violence will gradually diminish and fade out, provided weo can adequately satisfy all the needs of a reducedu world population. The results of rehousing experio ments strongly support this conjecture, for theyo show that juvenile delinquency declines strikinglyo in families moved from slums to good housing? provided the children have spent less than seven years in the slum environment. But in the history of human civilisation up to the present, many stresses? have been almost continuous, and the majox 
stresses of the population crises have recurred again and again, often at relatively short intervals. There has, therefore, up till now been no opportunity for complete recovery, and no age has been completely free from violence.

Even in mammals, marked differences are found between individuals, some being more aggressive than others. Observations by Beniest on mice, and by the Harlows on rhesus monkeys show that these differences can be related to differences in upbringing, which in the case of the monkeys may have two-generation affects. The same is undoubtedly true for man: it is a commonplace observation that some individuals are so sick through a particularly stressful upbringing, that they will commit atrocities as adults under negligible present stress, while some individuals, brought up under relatively relaxed conditions, are so thoroughly sane that they would never under any circumstances injure a child, for instance, no matter what the present stress to which they are subjected. Families differ, in short, in the microclimate of stress to which they are exposed, and human individuals accordingly provide a spectrum from the very sick to the very sane, with intermediate balances varying in the degree of present stress needed to tip them into destructive behaviour, and in the extent to which their destructiveness will reach. It is in relation to this variation that the stress on a whole society acts. We have seen that in monkeys, under relaxed conditions, the more sick and agressive individuals are quite unable to attain to high rank and influence and will thus be kept in order by the sane individuals who become leaders. Under severe stress, on the other hand, it is precisely the sickest who come to the top, like the chimpanzee dictator at Regent's Park or Diablo on Cayo Santiago. In the same way, in human societies, particularly sane leaders may arise in favourable conditions, leaders of average characteristics will predominate in intermediate conditions, and sick dictators will appear under severe stress.

\section{Birth control}

Our own century is one of the more violent ones in human history, and getting more so. Civilians, including women and children, made up 5 per cent of the dead in the First World War, between 50 and 75 per cent in the Second World War, and 84 per cent in Korea. From what is known of more recent conflicts, they are unlikely to have been less ferocious. Now even if we could tolerate, as human beings, the suffering and waste entailed by the population crisis response of social tension and violence, we can no longer afford it even for its own old evolutionary function, since a world war with modern weapons, far from sparing our food resources, would irretrievably damage them by its ecological effects. Fortunately, all the evidence we have considered points to the means of averting all this. If we can control our birth-rates by eliminating unwanted births, then we can do what no animal can do and what no previous human civilisation has succeeded in doing. We can substitute voluntary birth control for involuntary death control, what Paul Leyhausen has called 'the old, cruel methods by which Nature balanced our numbers'.

In 1976, world expenditure on birth control was estimated as about three billion dollars, compared with well over 200 billion dollars on military expenditure. This is very heartening, since it is evident how easily birth control expenditure could be greatly increased. Voluntary birth control programmes rapidly save many times the small outlay required. In Mecklenburg County, North Carolina, for instance, one such programme is estimated to have saved twenty times its operating costs (through reduced demand for social welfare payments) within three years. Even such large benefit-cost ratios as this may be underestimates. Forssman and Thuwe studied I20 Swedish children born after their mothers had applied for therapeutic abortion (on psychiatric grounds) and been refused, comparing them with an appropriate control series of the same size. Compared with the controls, the unwanted children were more often registered for psychiatric services, and listed more often for criminal behaviour and drunken misconduct; more of them received psychiatric care, were educationallie subnormal, and got public assistance; and more of the unwanted females than the control female married early and had children early. It is clear that unwanted children are likely to cost a society more than wanted ones, not to speak of the saving in burdens other than financial ones.

There is evidence from many parts of the world of people's readiness to use birth control facilities, if only they are provided, Dey and Potts have described the case of a very poor district of Calcutta, with a population of 30,000 . As soon as oral contraceptives were distributed in 1968, 2552 women began to use them, a higher rate of use than in the United Kingdom. Even after the government stopped the free supply, it was found in 1973 that 643 women were buying contraceptives, spending Io per cent or more of their minuscule disposable $\frac{D}{O}$ incomes. More than 90 per cent said they would still be using contraceptives if available free. From $N$ evidence such as this, it seems clear that governments have only to give the people the tools-contraceptive $N$ information and facilities, really effective abortion $\mathbb{W}$ on demand-and they will finish the job of removing 2 unwanted births. This is likely, as has been shown $c$ for several countries, to bring about massive $\mathbb{D}$ reduction in birth-rates.

\section{Conclusion}

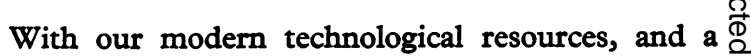


world population substantially reduced by voluntary birth control, we can find out how to create, for the first time in history, truly relaxed conditions for human societies. Everything we know of mammals and man suggests that, if we can do this, we can shunt out the population crisis response, solve the problem of violence, and build a lasting and creative civilisation. We can choose whether our species is to be kindly, merciful and generous, or diabolically malignant; for it is the same creature, under different conditions of stress.

\section{References}

${ }^{1}$ Apart from the three sources listed as references 2,3 and 4 , below, complete documentation for all the facts given in this paper will be found in the following publications of ours:

Russell, C (1970), Guy's hospital gazette, 84, 24I-5.

Russeli, C (1975). Biology and human affairs, 40, 77I00.

Russell, C \& Russell, W M S (1968). Violence, monkeys and man. London, Macmillan,

Russell, C \& Russell, W M S (1970). Australian natural history, 16, 429-32.

Russell, C \& Russell, W M S (197I). Overcrowding and Social Tension. in: Can Britain survive? (ed. E Goldsmith) 20I-IO. London, Stacey.
Russell, C \& Russell, W M S (1971). Impact of science on society, UNESCO 21, 63-74.

Russell, C \& Russell, W M S (1978). Biology and human $\stackrel{\curvearrowright}{\curvearrowright}$ affairs, 43, I-3r.

Russell, C \& Russell, W M S (1979). Scarcities and $\overrightarrow{\bar{n}}$ Societal Objectives. in: Growth without ecodisasters? ?़ (ed. N Polunin) 409-29, London, Macmillan (in $\overrightarrow{\vec{F}}$ press).

Russell, W M S (1971). Prices, Wages and Population. in: Can Britain survive? (ed. E Goldsmith) 2 I I-20. London, Stacey.

Russell, W M S (1976). Biology and human affairs, 41, 109-37.

Russell, W M S (1977). Britain and the Ecologicalis Crisis. in: Britain's crisis in sociological perspective $\vec{\circ}$ (ed. M B Hamilton and K G Robertson) 28-38. University Reading.

Russell, W M S The Palaeodemographic View. in: Disease in ancient man (proceedings of a joint $\overline{3}$ conference of the Royal Society of Medicine and $\bar{\Phi}$ the Academy of Medicine of Toronto, 1979), in

preparation.
Russell, W M S and Russell, C (1976). Update: journal $\vec{D}_{\infty}$ of postgraduate general practice, 12, 571-88.

${ }^{2}$ Radzinowicz, L \& King J (1979). The growth of crime ${ }^{\supset}$ (Pelican edition) Penguin Books, Harmondsworth.

${ }^{3}$ Brindley, T S (1973). Biology and human affairs, 38,

${ }^{4}$ Galle, O R, Gove, W R \& McPherson, J Miller. (1972) Science, 176, 23-30. 